\title{
Metal Erosion due to Particles at High Velocity and Temperature
}

\author{
Bushra Zaheer, Emad Uddin, Aamir Mubashar, Zaib Ali, Nabeel Arif \\ Department of Mechanical Engineering, School of Mechanical and Manufacturing Engineering (SMME) \\ National University of Sciences and Technology (NUST) \\ Islamabad, Pakistan, 44000
}

\begin{abstract}
Study of erosion is of great of importance because of its impact on the overall metal degradation. The main purpose is to minimize erosion because in most systems it is one of the biggest reasons of failure. Different models have been studied recently; however they are all at subsonic speed with standard environmental conditions. Erosion can be seen at the places where the interaction is for smaller time such that corrosion can't take place and all the loss of mass is due to the impact. In this study the numerical simulation was conducted to calculate the erosion rate at high supersonic speed. The problem is specifically related to the erosion at the speed range of $2000-3000 \mathrm{~m} / \mathrm{s}$ and temperature as high as $3000 \mathrm{~K}$. An analytical model is also implemented to compare and validate numerical results as well as to propose a better analytical model for high speed.
\end{abstract}

Keywords: Erosion, Supersonic, Failure.

\section{Introduction}

Erosion is phenomena in which the dimension is lost due to the interaction of two surfaces. Erosion is a slow process of removal of metallic surface due to any mechanical or electrical action. The major reasons for erosion are: friction produced due to rubbing of surfaces, cavitation, action of any fluid on the surface or wear [1]. This study is about the erosion of ductile metal due to impact of high velocity particles. Erosion is a type of wear in which the surface is damaged because of continuous impact and being subjected to elevated localized stresses. We can see that this particular problem related to impact of particle has great significance in practical field [2]. Cost minimization and longer run of the setup is one very important aim for any system prone to erosion. Wear is a major factor in increasing maintenance cost as well as causes system failure. We can see the impact of erosion in the major industries including, turbine blades in gas-turbine aero-engines, power plants, jet nozzles and guide vanes.

Recent studies have been conducted on the erosion of material at subsonic speed. It was suggested that the erosion is mostly dependent on the ratio of curvature and initial velocity [3, 4]. Other studies also considered angle of impacting particles on the erosion rate [5]. In our case the angle is $0^{0}$ as the flow is along the surface of material. After reviewing several other models it can be concluded that the erosion rate of the material is dependent upon the various parameters including velocity of impact, temperature and pressure conditions of impacting particles, angle of impact, time of exposure, particle concentration, properties of impacting particle and erodent (substrate) and particle size [6]. The erosion is caused by cyclic impact of particles over the surface due to which the stresses are exceeded from the yield point [7]. Plastic deformation occurs on and around the point of impact. Stresses increases and fracture point is approached due to continuous impact, furthermore plastic deformation ceases, at this point the surface of the martial losses it ductility and small fragments peel off from the surface .

The analytical model was given by Levi's on the basis of experimental results. The Levi's model suggested that the erosion of a material is dependent upon various parameters including mass of impacting particles, initial particle velocity, target material properties, density of the impacting particles and plastic zone volume [8]. Levi's [2] presented an analytical model and derived an equation for parameter at which the erosion rate is dependent. 


$$
E_{\text {parameter }}=\frac{\left[1-\frac{3.06 \times H \times 5 / 4}{\mathrm{~V} i / 2 \times \rho_{p} / 4} \cdot\left(\frac{1-u_{t}^{2}}{E_{t}}+\frac{1-u_{p}^{2}}{E p}\right)\right]}{T L}
$$

where $V_{i}$ is the initial velocity, $\rho_{\mathrm{p}}$ is the density of impacting spherical particle, $\mathrm{H}$ is the hardness of target material, $\mathrm{u}_{\mathrm{t}}$ and $\mathrm{u}_{\mathrm{p}}$ are the poisson's coefficients and $\mathrm{E}_{\mathrm{t}}$ and $\mathrm{E}_{\mathrm{p}}$ are the elastic modulus of the target and particle material respectively. A comparison is made between the experimental erosion rate and the analytically calculated erosion parameter. The setup consists of air compressor, pressure regulator and a flow meter. A feeder fed erodent in the air, detail of the whole system was explained in detail [2]. The samples were subjected to exposure for different time intervals starting from 30 to 240 minutes. Using that experimental data, a relationship is developed using curve fit method.

$$
\text { Erosion Rate }=6.8272+3.1526 x\left(R^{2}=0.99297\right)
$$

\section{Aim of this Research}

Levi's Model predicts accurately at low velocity. The velocity factor doesn't have significant impact on erosion parameter and erosion rate. If we calculate the erosion rate at different supersonic velocities using analytical model, we get the following results

Table 1: Erosion rate and erosion parameters at supersonic speed using Levi's Model.

\begin{tabular}{|c|c|c|}
\hline $\mathbf{V}_{\mathbf{i}}$ & Erosion Parameter & Erosion Rate $\left(\mathbf{m m}^{\mathbf{3}} / \mathbf{m i n x 1 0} \mathbf{3}^{\mathbf{3}}\right)$ \\
\hline 340 & $7.04 \mathrm{E}-01$ & 9.05 \\
\hline 680 & $7.43 \mathrm{E}-01$ & 9.17 \\
\hline 1020 & $7.61 \mathrm{E}-01$ & 9.23 \\
\hline 1360 & $7.71 \mathrm{E}-01$ & 9.26 \\
\hline
\end{tabular}

Aim of our work is to conduct a numerical study to understand the effect of different parameters on erosion Rate of previously listed materials and suggest best material with minimum erosion rate.

\section{Research Methodology}

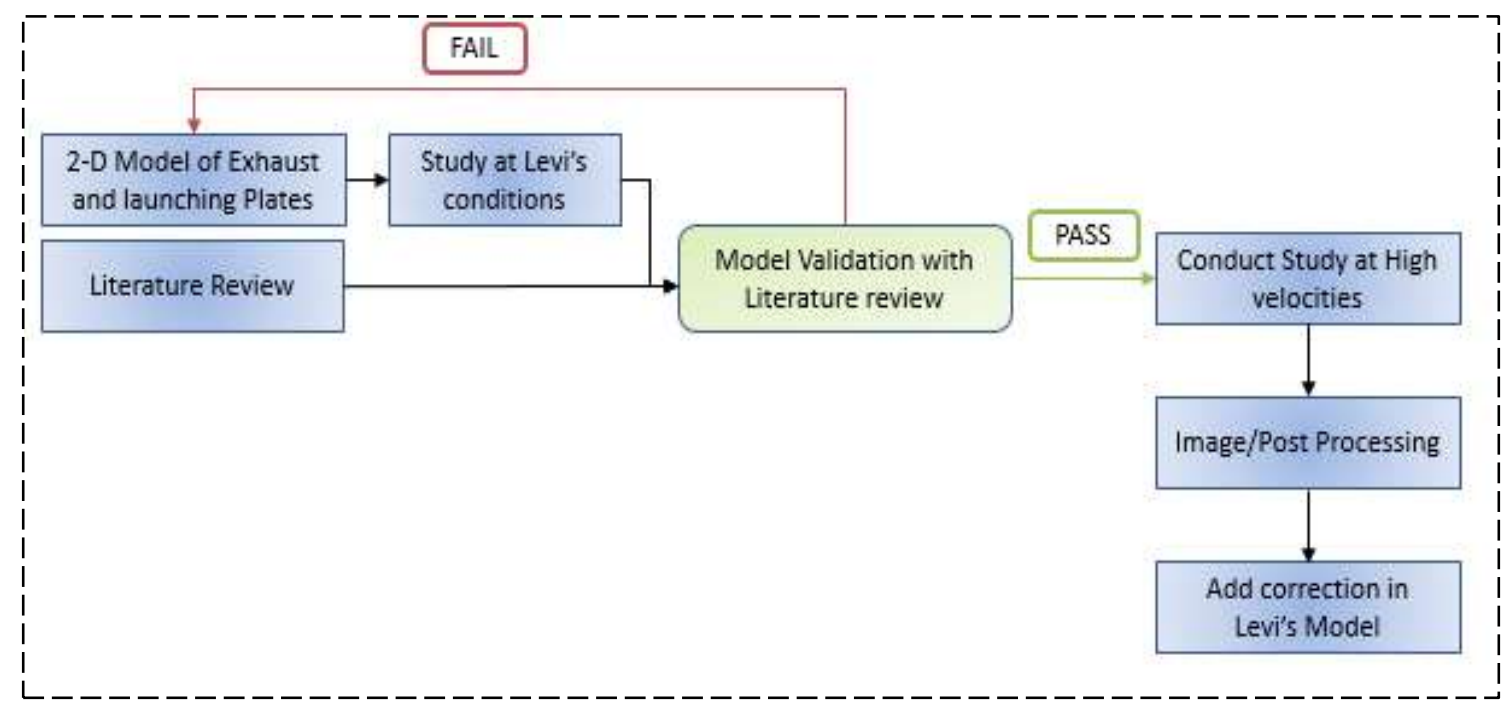

Fig. 1: Research methodology. 


\section{Numerical Solution}

As the surface was impacted by high velocity solid particles, damage can be seen on the surfaces. This is also affected by the change in pressure, temperature and other different parameters $[9,10,11]$. In past few decades, computational fluid dynamics (CFD) emerges as a widely used technology in almost all the industrial fields. Nowadays CFD software using discrete phase model is widely used in different fields i.e. parametric study of continuous phase on erosion rate [12, 13], simulate the scenario to calculate erosion rate and modify the model to minimize it. [14, 15]. Study of physical parameters is not enough to understand this phenomenon. The trajectory of impacting particles its velocity, temperature and pressure are also important. By using appropriate software, erosion can be accurately measure because they keep in account the multiphase flow and hydrodynamics parameters. [16].

\subsection{Computational Model}

To investigate the rate of erosion other than experimental techniques, model to predict erosion rate using CFD is also a good approach [17]. Here we used euler lagrange frame of reference. The model consists of nozzle, exhaust gases and substrate. Exhaust gases comprises of air along with $4 \%$ alumina particles, and four different type of substrate made up of different materials so as to compare the results of each material.

The reason for using euler lagrange model is that the trajectory of the impacting particles and their state e.g. their velocity, temperature, density, composition and other properties is followed in time and space. By solving and integrating equations of mass, motion and energy for every particle of the system, discrete element method also knows as DEM is used.

\subsection{Governing Equations}

Different Equations are used to carry this study every material has assigned different Equation of States and Strength models. The equation of state is a basic representation of a substance which help in applying the fundamental principles of thermodynamics and hydrodynamics to any material. [18]

ANSYS AUTODYN version 18 was used, linear equation of state (EOS) was used for substrate and impacting particles. Ideal Gas EOS is used for air considering all the collision between the atoms and molecules to be perfectly elastic and volume to be constant.

$$
P V=n R T
$$

where $\mathrm{P}$ is the pressure, $\mathrm{V}$ is the volume, $\mathrm{n}$ is the number of moles, $\mathrm{R}$ is the ideal gas constant and $\mathrm{T}$ is the temperature. Strength model is used to predict the deformation, fracture and damage to any material [19]. Johnson and cook model is used for substrate and impacting particle. Johnson-cook equation is used for very high strain rate [20].

\subsection{Model Validation}

The validation study was conducted using Levi's experimental condition and the material properties. Same velocity was used i.e. $40 \mathrm{~m} / \mathrm{s}$ and Temperature $293 \mathrm{~K}$ in the CFD. The comparison of result is as under.

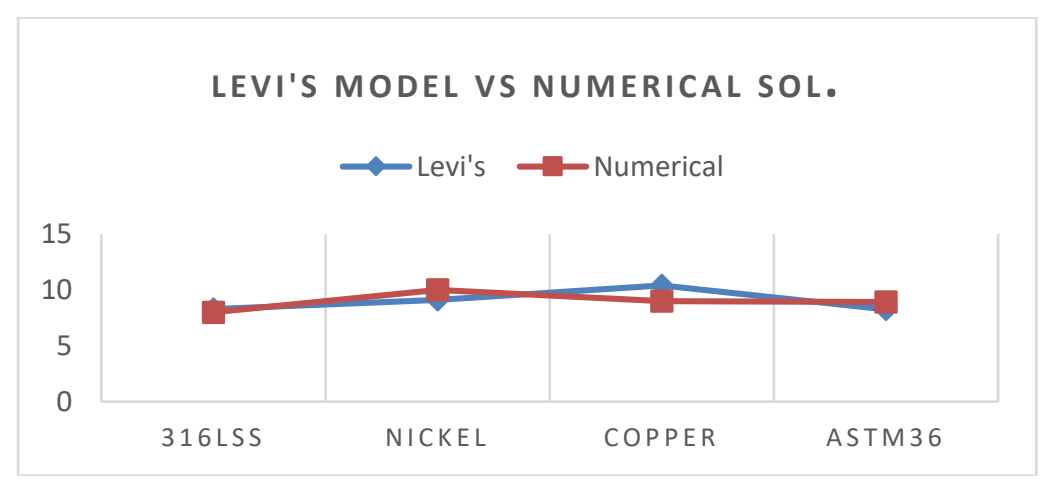

Fig. 2: Erosion rate comparison between Levi's model and numerical studies. 


\section{Post Processing}

To calculate Erosion Rate volumetrically so for post processing images were taken before and after the study was conducted.
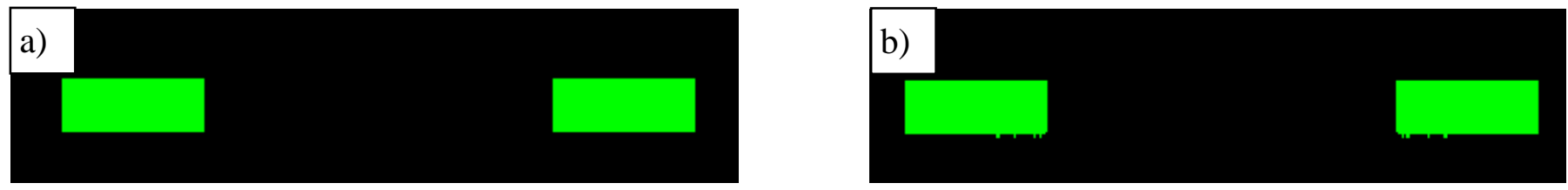

Fig. 3: Substrate plate image at a) $t=0$ and $b) t=5 \cdot 1 e^{-2}$.

The code is written in python programming language. OpenCv is used for image processing and computer vision functions. Using that code the image at $\mathrm{t}=5.1 \mathrm{e}^{-2}$ is subtracted from image at $\mathrm{t}=0$ and erosion was calculated

\section{Results and Discussion}

\subsection{Effect of Velocity on Erosion Rate:}

Studies were conducted by varying velocity keeping all other parameters constant. Velocity is varied from Mach 1 - 4. The data calculated through this study is as under

Table 2: Erosion rate at different Velocities.

\begin{tabular}{|c|c|}
\hline Velocity & $\begin{array}{c}\text { E.R } \\
\left(\mathrm{mm}^{3} / \mathrm{sec}\right)\end{array}$ \\
\hline 340 & 65.5 \\
\hline 680 & 90.1 \\
\hline 1020 & 102.3 \\
\hline 1360 & 126 \\
\hline
\end{tabular}

We can see that the increase in erosion rate is higher with increase in velocity as compared to what we can get from out analytical model. To compare we can see their graphical representation

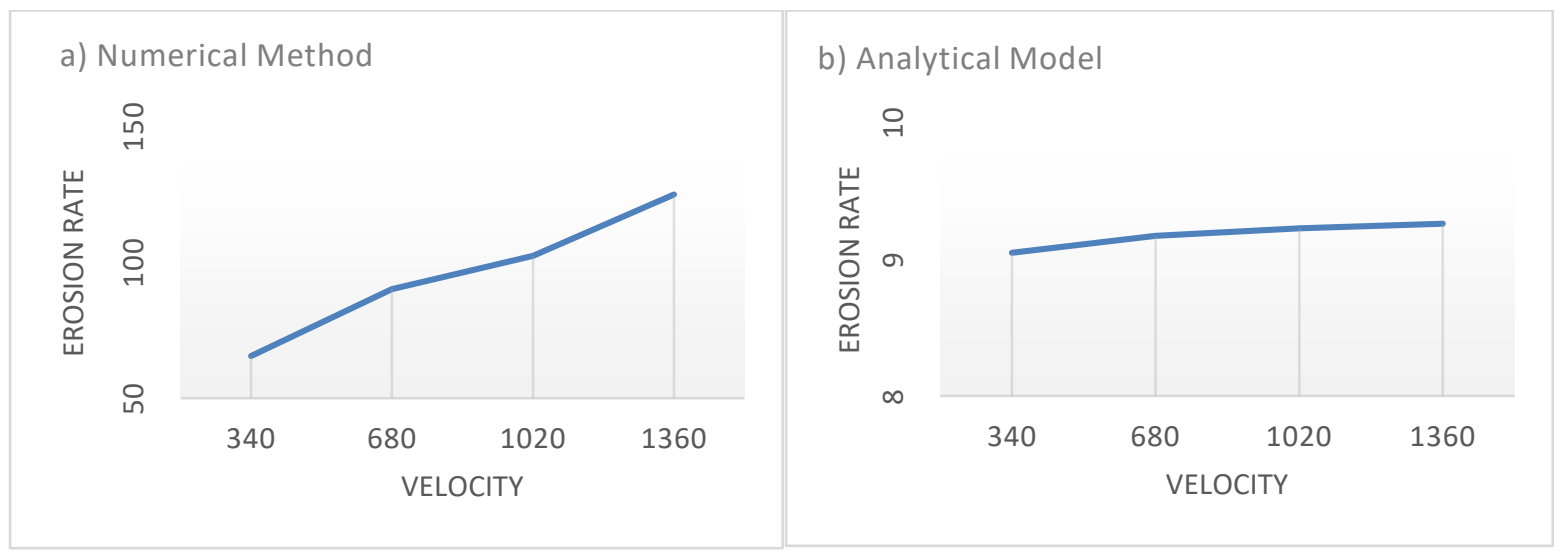

Fig. 5: Comparison between a) numerical results and b) Levi’s analytical model results.

\subsection{Correction Factor}

From analytical solution we can see the equation shows negligible impact of velocity e.g. only $0.21 \mathrm{e}-{ }^{3} \mathrm{~mm}$ difference can be seen if we increase the velocity from Mach 1 to 4. 
Erosion rate $=-0.0005 \mathrm{v}+8.9 \mathrm{e}^{-3}$

Using curve fit method; we can find the actual relation between velocity and erosion rate

Erosion rate $=0.00000 \mathrm{v}^{2}-0.0634 \mathrm{v}+45.6$

\subsection{Effect of Material Properties on Erosion Rate}

The data shown in Table 3 is the erosion rate while using different materials and hence different material properties.

Table 3: Erosion rate of different materials at different velocities.

\begin{tabular}{|c|c|c|c|c|}
\hline Velocity & ASTM A36 & Copper & Nickle & 316L SS \\
\hline $\mathbf{3 4 0}$ & 65.5 & 46.2 & 52.8 & 79.2 \\
\hline $\mathbf{6 8 0}$ & 90.1 & 54.5 & 57.9 & 101.1 \\
\hline $\mathbf{1 0 2 0}$ & 102.3 & 103.3 & 62.5 & 112.0 \\
\hline $\mathbf{1 3 6 0}$ & 126 & 113.1 & 67.9 & 126.3 \\
\hline
\end{tabular}

From the results we can see that the erosion rate with the least shear strength erodes more with increase in velocity, however the erosion rate of the material having high yield strength at low velocity is lesser.

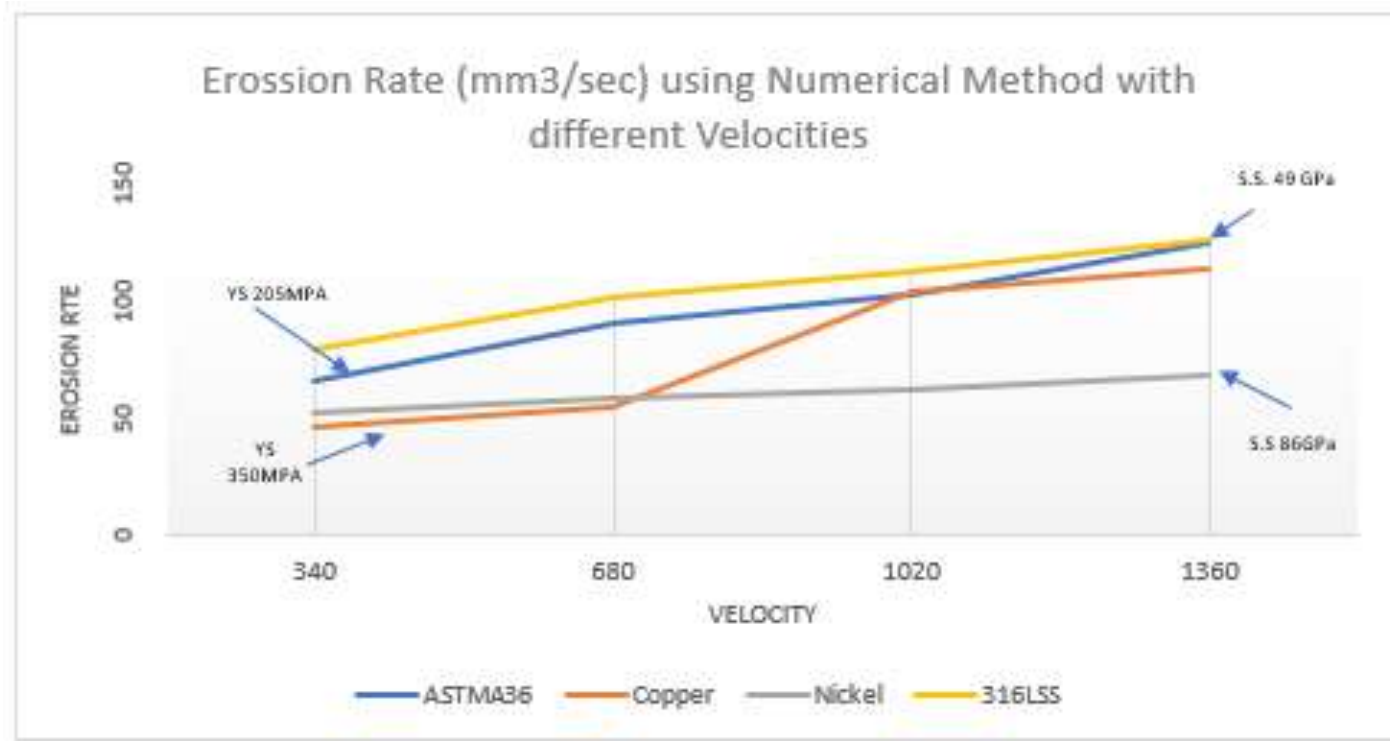

Fig. 6: Erosion rate of different materials at variable velocities.

\section{Conclusion}

From the above results and discussion this conclusion can be deduced that for high velocity of $1360 \mathrm{~m} / \mathrm{s}$, Nickel is most suitable keeping in view the erosion rate. Copper is a good material choice till $680 \mathrm{~m} / \mathrm{s}$, but for $1020 \mathrm{~m} / \mathrm{s}$ onwards all the metals except nickel behaves very similar with some difference in the erosion rate. Alloys can be used with optimum yield strength and shear strength according to the velocity we are working with. Plastic strain has high significance so that is why yield point is important in terms of erosion rate but at high velocity shear strength plays vital role. With reference to analytical model and its correction, at high velocity the Levi's model can't work. The correction factor that is suggested in can be added for calculation of better results at high velocities. 


\section{References}

[1] The Great Soviet Encyclopedia, 3rd Ed. The Gale Group, 1970-1979.

[2] A. K. Cousens, The Erosion of Ductile Metals. Solid Particle Impact, 1984.

[3] F. A. Bikbaev, V. I. Krasnov, M. Z. Maksimenko, and V. L. Berezin, "Main Factors Affecting Gas Abrasive Wear of Elbows in Pneumatic Conveying Ducting," Chem. Petrol. Eng., vol. 8, pp. 465-466, 1972.

[4] J. K. Edwards, B. S. McLaury, and S. A. Shirazi "Modeling Solid Particle Erosion in Elbows and Pugged tees," ASME J. Energy Resource. Technol., vol. 123, pp. 277-284, 2001.

[5] S. M. El-Behery, M. H. Hamed, K. A. Ibrahim, and M. A. El-Kadi, "CFD Evaluation of Solid Particles Erosion in Curved Ducts," J. Fluids Eng, vol. 132, no. 7, 2010.

[6] David Richard, "The Erosion of Metals," submitted to the University of Cambridge for the degree of Doctor of Philosophy, 1980.

[7] J.G.A. Bitter, “A Study of Erosion Phenomena Part I," Wear, vol. 6, pp. 5-21, 1963.

[8] B. F. Levin, K. S. Vecchio, J. N. DuPont, and A. R. Marder, "Modeling Solid-Particle Erosion of Ductile Alloy," Metallurgical and Materials Transactions A, vol. 30A, 1999.

[9] S.-P. Zeng, X.-W. Yang, Q.-M. Zhang, C.-B. Xu, J. Liu, Han-yukun, X. Liang, and G.-M. Yao, "Investigating on the prediction model of sulfur deposition in high sour gas-well," J. Procedia Eng., vol. 29, pp. 4267-4272, 2012.

[10] Z. Fan, X. Hu, J. Liu, L. Hongchuan, and F. Jinwen, "Stress corrosion cracking of L360NS pipeline steel in sulfur environment," J. Petrol., vol. 3, no. 3, pp. 377-383, 2017.

[11] L. He, X. Guo, "Study on sulfur deposition damage model of fractured gas reservoirs with high-content H2S," $J$. Petrol., vol. 3, pp. 321-325, 2017.

[12] C. Xianghui, B. S. McLaury, and S. A. Shirazi "Application and experimental validation of a computational fluid dynamics (CFD)-based erosion prediction model in elbows and plugged tees," J. Computers Fluids, vol. 33, no. 10, pp. 1251-1272, 2004.

[13] H. Zhu, Q. Pan, W. Zhang, F. Guang, and L. Xue, "CFD simulations of flow erosion and flow-induced deformation of needle valve: effects of operation, structure and fluid parameters," Nucl. Eng. Des., vol. 273, pp. 396-411, 2014.

[14] H. P. Rani, T. Divya, R. R. Sahaya, "CFD study of flow accelerated corrosion in 3D elbows," J. Annals Nucl. Energy, vol. 69, pp. 344-351, 2014.

[15] Y. I. Oka, K. Okamura, T. Yoshida, "Practical estimation of erosion damage caused by solid particle impact: Part 1: effects of impact parameters on a predictive equation," J. Wear, vol. 259, pp. 95-101, 2005.

[16] E. Zhang, D. Zeng, H. Zhu, S. Li, D. Chen, J. Li, Y. Ding, and G. Tian, "Numerical simulation for erosion effects of three-phase flow containing sulfur particles on elbows in high sour gas fields," Petroleum, vol. 4, no. 2, pp. 158-167, 2018.

[17] S. Gerber, M. Oevermann, F. Behrendt, "An Euler-Lagrange modeling approach for the simulation of wood gasification in fluidized beds," Berlin Institute of Technology School of Process Sciences and Engineering Department of Energy Engineering Chair for Energy Process Engineering and Conversion Technologies for Renewable Energies Fasanenstr., vol. 89, 10623 Berlin, Germany.

[18] Vladimir Evgenievich Fortov. (2011). Equation of State [Online]. Available: http://www.thermopedia.com/content/734/

[19] G. T. Gray, P. J. Maudlin, L. M. Hull, Q. K. Zuo and S.-R. Chen, "Predicting material strength, damage, and fracture the synergy between experiment and modelling," Los Alamos Science, no. 29, 2005

[20] Identification of Johnson-Cook Equation Constants using Finite Element Method Michał GRĄZKA, Jacek JANISZEWSKI Military University of Technology, Institute of Armament Technology Kaliskiego. 